\title{
A ESTABILIDADE NO EMPREGO \\ E O EMPREGADO EM FUNÇÃO DE CONFIANÇA
}

\author{
André Araújo de Oliveira*
}

\section{RESUMO}

Propôs-se no presente artigo explorar a controvérsia a respeito do empregado estável, partindo do caso concreto debatido no Tribunal Superior do Trabalho, quanto ao empregado estável decorrente da condição de dirigente sindical, em confronto com o dispositivo do art. 499 da CLT, pelo qual não há estabilidade para os empregados que estejam ocupando cargo de confiança.

Palavras-chave: Direito do Trabalho - Estabilidade Cargo de Confiança - Dirigente Sindical.

\section{ABSTRACT}

It was proposed in this article to explore the controversy regarding the stable employee, starting from the specific case discussed in the Superior Labor Court, regarding the stable employee resulting from the condition of union leader, in comparison with the art. 499 of the CLT, for which there is no stability for the employees who are occupying a position of trust.

\section{INTRODUÇÃO}

Sabe-se que a estabilidade no emprego confere garantias ao empregado no exercício de suas funções, afastando o risco de retaliações por parte do empregador. Temos várias

\footnotetext{
* Mestre em Direitos Difusos e Coletivos pela UNIMES - Universidade Metropolitana de Santos e Doutorando em Direito do Trabalho pela PUC - Pontifícia Universidade Católica de São Paulo; advogado e professor licenciado da Universidade Metodista de São Paulo - UMESP.
} 
situações que são acobertadas por essa proteção, como no caso dos membros da CIPA e também da condição de dirigente sindical, sem falar em demais garantias decorrentes de benefícios previstos na Lei ou em Convenções Coletivas de Trabalho. Nesse segundo bloco para o qual se propõe didática e inicial divisão, temos, por exemplo: a estabilidade da gestante, a acidentária, previstas em Lei, e a estabilidade pré-aposentadoria, prevista normalmente em normas coletivas.

O princípio base que dá guarida ao instituto da estabilidade é o da continuidade da relação de emprego. Em que pese o poder potestativo do empregador, fato é que a estabilidade funciona como uma limitação claramente imposta, de forma positivada, em reforço ao referido princípio que rege a relação de trabalho.

Gustavo Filipe Barbosa Garcia conceitua estabilidade como

o direito do empregado de permanecer no emprego, restringindo o direito do empregador de dispensá-lo sem justa causa ou de forma arbitrária, só se concretizando a cessação contratual em caso de falta grave, força maior, força maior que determine a extinção da empresa, ou cessação das atividades da empresa ${ }^{1}$.

Há uma clara limitação ao empregador na demissão do empregado estável, porém esta não é absoluta. Desde que presente uma causa justificada prevista em Lei, a demissão poderá ser efetivada.

\section{AS DIFERENTES MODALIDADES DE ESTABILIDADE}

Tecnicamente, a estabilidade prevista em lei é a decenal, conforme melhor abordado no item 1.1 infra. A doutrina tem adotado a terminologia "garantia de emprego" para se referir à estabilidade provisória, que também não se confunde com a estabilidade plena, qual seja, a decenal. De todo modo, esta

1 Curso de Direito do Trabalho. Gustavo Filipe Barbosa Garcia. - $2^{\text {a }}$ ed. rev. Atual. e ampl. São Paulo: Método, 2008. P. 613. 
diferenciação nos conceitos não compromete o entendimento do tema, haja vista que a proposta do presente artigo é contrapor a estabilidade e os ocupantes de cargo de confiança, bem como pelo fato de todas as estabilidades atualmente previstas em nosso ordenamento jurídico, à exceção da decenal, serem tidas como "garantia de emprego".

Ressalta-se que a estabilidade é de emprego e não de salário. Nesse sentido, não cabe ao empregador deliberar pela substituição da manutenção do emprego pela correspondente indenização financeira. Exceção que merece registro, contudo, é a previsão do art. 496 da CLT, pois no caso do empregador pessoa física, abriu-se a possibilidade da indenização em dobro em detrimento da reintegração. Faz sentido o referido dispositivo legal em face das dificuldades de convivência que possivelmente se concretizariam na hipótese de retorno ao trabalho daquele empregado anteriormente desligado.

Sem o intuito de esgotar o tema, faz-se necessário traçarmos breves comentários sobre as principais modalidades de estabilidade previstas em nossa legislação.

\subsection{A ESTABILIDADE DECENAL}

A estabilidade por tempo de serviço prevista no art. 492 da CLT vigorou até a entrada em vigor da Constituição Federal de 1988, pois naquele momento houve a substituição pela indenização por tempo de serviço no formato do FGTS. Houve, contudo, preservação do direito adquirido para os que já tivessem alcançado o período de dez anos quando da promulgação da Carta Magna. Importante salientar, ainda, que mesmo em período pré-Constituição, já havia a possibilidade de o empregado optar pelo regime do FGTS em detrimento da estabilidade decenal.

Como forma de reforçar a proteção conferida pela Lei, havia, ainda, o Enunciado 26 do TST que presumia como obstativa à estabilidade a despedida do empregado que alcançasse nove anos de serviço na empresa. Como derradeira 
proteção conferida a esta modalidade de estabilidade à época de sua vigência, tem-se a formalidade insculpida no art. 500 da CLT que indicava a necessidade de homologação da entidade sindical ou do Ministério do Trabalho.

\subsection{A ESTABILIDADE DO DIRIGENTE SINDICAL}

Tanto a Constituição Federal como a CLT tratam da estabilidade do dirigente sindical. Aqui há clara proteção àquele que, não raras as vezes, coloca-se em posição de conflito junto ao empregador na defesa dos interesses da categoria. Nesse sentido, a proteção ganha especial relevância para dar efetividade ao princípio da liberdade sindical e, de modo geral, ao da proteção ao trabalhador.

A estabilidade nasce com a candidatura e perdura até um ano após o final do mandato, que é de 3 anos, mesmo que eleito como suplente. Como o sistema é confederativo, a estabilidade contempla também os dirigentes das federações e confederações, conforme preceituam os artigos 534 e 535 da CLT.

Cabe chamarmos atenção para a quantidade de dirigentes estáveis. Por vários anos verdadeira insegurança jurídica vigorou no quesito "quantidade de dirigentes e de seus respectivos suplentes", pois muitos sindicatos possuíam em suas Diretorias número excessivo de dirigentes e de suplentes. Assim, cabia à Jurisprudência acomodar os exageros. Fato é que em 2012 o TST atualizou a Súmula $369^{2}$ e definiu o número de

2 Súmula $n^{\circ} 369$ do TST

DIRIGENTE SINDICAL. ESTABILIDADE PROVISÓRIA (redação do item I alterada na sessão do Tribunal Pleno realizada em 14.09.2012) - Res. 185/2012, DEJT divulgado em 25, 26 e 27.09.2012

I - É assegurada a estabilidade provisória ao empregado dirigente sindical, ainda que a comunicação do registro da candidatura ou da eleição e da posse seja realizada fora do prazo previsto no art. 543 , $\S 5^{\circ}$, da CLT, desde que a ciência ao empregador, por qualquer meio, ocorra na vigência do contrato de trabalho.

II - O art. 522 da CLT foi recepcionado pela Constituição Federal de 1988. Fica limitada, assim, a estabilidade a que alude o art. 543, § $3 .^{\circ}$, da CLT 


\section{A ESTABILIDADE NO EMPREGO E O EMPREGADO EM FUNÇÃO DE CONFIANÇA}

sete titulares e mais sete suplentes como detentores do direito à estabilidade. Por um bom período vários precedentes entendiam que o número de sete deveria acomodar tanto os titulares como os suplentes, mas atualmente não há mais espaço para dúvidas e os empregadores sabem exatamente o alcance da estabilidade.

Em que pese ramo do direito em que a formalidade não é requisito especial, para que a garantia de emprego do dirigente sindical seja válida, há necessidade de comunicação de sua candidatura ao empregador, a teor do art. 543, § $5^{\circ}$, da CLT. A ausência de observância de tal formalidade descaracterizará a garantia.

\subsection{A ESTABILIDADE DO MEMBRO DA CIPA}

A CIPA - Comissão Interna de Prevenção de Acidentes é composta por representantes dos empregados e do empregador. No caso dos empregados, são eleitos em escrutínio secreto os titulares e os suplentes para mandato de um ano, permitida uma recondução.

A garantia de emprego está prevista no art. 165 da CLT. Nesse caso, contudo, importante ressaltar que além da despedida sem justa causa, pode o membro da CIPA com garantia de emprego ser desligado por motivo técnico, econômico ou financeiro. Caberá ao empregador, na hipótese de ser demandado pelo empregado, comprovar em juízo a veracidade da motivação invocada.

\footnotetext{
a sete dirigentes sindicais e igual número de suplentes.

III - O empregado de categoria diferenciada eleito dirigente sindical só goza de estabilidade se exercer na empresa atividade pertinente à categoria profissional do sindicato para o qual foi eleito dirigente.

IV - Havendo extinção da atividade empresarial no âmbito da base territorial do sindicato, não há razão para subsistir a estabilidade.

$\mathrm{V}$ - O registro da candidatura do empregado a cargo de dirigente sindical durante o período de aviso prévio, ainda que indenizado, não the assegura a estabilidade, visto que inaplicável a regra do $\S 3^{\circ}$ do art. 543 da Consolidação das Leis do Trabalho.
} 
Nos termos da Súmula $339^{3}$ do TST, corroborando o art. 10, II, "a", do Ato das Disposições Transitórias, a garantia aplica-se também ao suplente.

O objetivo da proteção conferida é a busca incessante e ilimitada da segurança e saúde do empregado. Não fosse a estabilidade certamente ficaria comprometida a isenção dos representantes dos empregados na identificação de falhas internas, oportunidades de melhoria e medidas necessárias de responsabilidade do empregador.

Importante ressaltar a ausência de garantia na hipótese de extinção do estabelecimento, mesmo porque esta estabilidade não configura vantagem pessoal e sim legitimidade e autonomia para o exercício do mandato. Extinto o estabelecimento, o próprio fundamento de constituição da CIPA deixa de existir.

\subsection{A ESTABILIDADE DA GESTANTE}

A empregada gestante faz jus à garantia de emprego prevista no art. 10, inciso II, "b", do Ato das Disposições Constitucionais Transitórias, desde a confirmação da gravidez até cinco meses após o parto.

Tem direito à reintegração, caso ocorra durante o período de estabilidade, ou a indenização correspondente, se finalizado este. Isso a teor da Súmula 244 do TST ${ }^{4}$.

\footnotetext{
3 Súmula $\mathrm{n}^{\circ} 339$ do TST
}

CIPA. SUPLENTE. GARANTIA DE EMPREGO. CF/1988 (incorporadas as Orientações Jurisprudenciais $n^{\circ}$ s 25 e 329 da SBDI-1) - Res. 129/2005, DJ 20, 22 e 25.04.2005

I - O suplente da CIPA goza da garantia de emprego prevista no art. 10, II, “a”, do ADCT a partir da promulgação da Constituição Federal de 1988. (ex-Súmula no 339 - Res. 39/1994, DJ 22.12.1994 - e ex-OJ no 25 da SBDI-1 - inserida em 29.03.1996)

II - A estabilidade provisória do cipeiro não constitui vantagem pessoal, mas garantia para as atividades dos membros da CIPA, que somente tem razão de ser quando em atividade a empresa. Extinto o estabelecimento, não se verifica a despedida arbitrária, sendo impossível a reintegração e indevida a indenização do período estabilitário. (ex-OJ n ${ }^{\circ} 329$ da SBDI-1 - DJ 09.12.2003)

4 Súmula $n^{\circ} 244$ do TST

GESTANTE. ESTABILIDADE PROVISÓRIA (redação do item III alterada na 


\section{A ESTABILIDADE NO EMPREGO E O EMPREGADO EM FUNÇÃO DE CONFIANÇA}

Esta mesma Súmula asseverou que o desconhecimento do estado gravídico pelo empregador não descaracteriza o direito da empregada.

Por certo período vigorou o entendimento de que a empregada contratada a termo certo não teria direito à estabilidade provisória, dentre elas a da condição de gestante. A Súmula 244 também chegou a regulamentar a matéria, mas o TST alterou o entendimento e conferiu interpretação oposta à que vinha sendo adotada. Desse modo, mesmo nos contratos por prazo determinado, em que pese a ciência do prazo inicialmente estipulado para seu fim, atualmente prevalece o entendimento de que a gestante goza de estabilidade provisória, não podendo seu contrato ser encerrado na data inicialmente convencionada.

Com relação à mãe adotante, mesmo que parte da doutrina defensa a existência de institutos jurídicos distintos, quais seja, o da licença maternidade e o da estabilidade provisória, importante destacar que em recente acórdão do TST, processo $n^{\circ}$. 200600-19.2008.5.02.0085, transitado em julgado em 22.10.2015, o entendimento foi o de que o desligamento da empregada inviabilizou acesso à licença maternidade, de modo que a empresa fora condenada ao pagamento do período correspondente aos meses de estabilidade. O Ministro relator asseverou que para a mãe adotante poder usufruir

sessão do Tribunal Pleno realizada em 14.09.2012) - Res. 185/2012, DEJT divulgado em 25, 26 e 27.09.2012

I - O desconhecimento do estado gravídico pelo empregador não afasta o direito ao pagamento da indenização decorrente da estabilidade (art. 10, II, "b” do ADCT).

II - A garantia de emprego à gestante só autoriza a reintegração se esta se der durante o período de estabilidade. Do contrário, a garantia restringe-se aos salários e demais direitos correspondentes ao período de estabilidade. III - A empregada gestante tem direito à estabilidade provisória prevista no art. 10, inciso II, alínea "b", do Ato das Disposições Constitucionais Transitórias, mesmo na hipótese de admissão mediante contrato por tempo determinado. 
da licença prevista no art. 392, A, necessariamente deveria gozar da estabilidade prevista no art. no art.10, II, "b", do ADCT da Constituição Federal de 1988.

\subsection{A ESTABILIDADE DO EMPREGADO ACIDENTADO}

$O$ art. 118 da Lei 8.213/1991 estabeleceu a garantia de emprego, pelo prazo mínimo de 12 meses, após a cessação do auxílio doença acidentário.

Nesse sentido, há necessidade de que o trabalhador tenha percebido o auxílio doença acidentário, ou seja, não basta a ocorrência do evento "acidente do trabalho", pois o prazo de afastamento deve superar os 15 primeiros dias, gerando, assim, a percepção do benefício previdenciário. Não apenas o acidente do trabalho gera a percepção dessa modalidade de benefício, mas também a doença profissional e a doença do trabalho.

Caso seja provado que a doença possuía vínculo com o trabalho, não sendo assim caracterizada por procedimento que escapa à alçada do empregado, a formalidade das condições previstas no art. 118 pode ser afastada. Nesse sentido é que dispõe a Súmula 378 do TST $^{5}$.

5 Súmula $\mathrm{n}^{\circ} 378$ do TST

ESTABILIDADE PROVISÓRIA. ACIDENTE DO TRABALHO. ART. 118 DA LEI N ${ }^{\circ} 8.213 / 1991$. (inserido item III) - Res. 185/2012, DEJT divulgado em 25,26 e 27.09 .2012

I - É constitucional o artigo 118 da Lei $\mathrm{n}^{\circ} 8.213 / 1991$ que assegura o direito à estabilidade provisória por período de 12 meses após a cessação do auxílio-doença ao empregado acidentado. (ex-OJ n ${ }^{\circ} 105$ da SBDI-1 inserida em 01.10.1997)

II - São pressupostos para a concessão da estabilidade o afastamento superior a 15 dias e a conseqüente percepção do auxílio-doença acidentário, salvo se constatada, após a despedida, doença profissional que guarde relação de causalidade com a execução do contrato de emprego. (primeira parte - ex-OJ no 230 da SBDI-1 - inserida em 20.06.2001)

III - III - O empregado submetido a contrato de trabalho por tempo determinado goza da garantia provisória de emprego decorrente de acidente de trabalho prevista no art. 118 da Lei $n^{\circ} 8.213 / 91$. 


\section{A ESTABILIDADE NO EMPREGO E O EMPREGADO EM FUNÇÃO DE CONFIANÇA}

Em respeito ao princípio da norma mais favorável é que deve ser entendida a expressão "mínimo de 12 meses" prevista no art. 118. Nada impede que outra norma venha a majorar esse prazo de estabilidade. Se nenhuma outra normativa estender o prazo de garantia de emprego, prevalece a regra geral dos 12 meses.

Assim como no caso de estabilidade à gestante, aqui também muito se debateu sobre a garantia de emprego no caso de contrato por prazo determinado. Não fazendo sentido que para uma modalidade houvesse mudança de entendimento e para outra não, o desfecho seguiu a mesma lógica no sentido de preservar o emprego mesmo nos casos em que já se tem conhecimento do termo final do contrato. É a prevalência do princípio da proteção ao trabalhador.

Mesma conclusão vale para o acidente ocorrido no curso do aviso-prévio.

Conforme inicialmente apontado, outras estabilidades existem em nosso ordenamento jurídico, mas entendemos por bem em destacar essas indicadas nos itens anteriores. Podemos, contudo, mencionar outras que não serão detalhadas no presente artigo: estabilidade do Conselho Curador do FGTS, empregado eleito diretor de cooperativa, empregado membro da Comissão de Conciliação Prévia, empregado reabilitado e empregado portador de deficiência.

\section{A PREVISÃO DO ART. 499 DA CLT: AUSENNCIA DE ESTABILIDADE PARA CARGOS DE CONFIANÇA}

A previsão do art. 499 da CLT está inserida no capítulo que trata da estabilidade decenal, porém sem indicação expressa de que apenas a ela se refere. Por outro lado, o título no qual consta inserido o referido capítulo, trata de modo geral do "Contrato Individual de Trabalho".

Por força do que se pretende explorar no presente artigo, importante transcrever o art. 499 ora objeto de análise: 
Art. 499 - Não haverá estabilidade no exercício dos cargos de diretoria, gerência ou outros de confiança imediata do empregador, ressalvado o cômputo do tempo de serviço para todos os efeitos legais.

$\S 1^{\circ}$ - Ao empregado garantido pela estabilidade que deixar de exercer cargo de confiança, é assegurada, salvo no caso de falta grave, a reversão ao cargo efetivo que haja anteriormente ocupado.

$\S 2^{\circ}$ - Ao empregado despedido sem justa causa, que só tenha exercido cargo de confiança e que contar mais de 10 (dez) anos de serviço na mesma empresa, é garantida a indenização proporcional ao tempo de serviço nos termos dos arts. 477 e 478. $\S 3^{\circ}$ - A despedida que se verificar com o fim de obstar ao empregado a aquisição de estabilidade sujeitará o empregador a pagamento em dobro da indenização prescrita nos arts. 477 e 478 .

A indagação que se faz necessária é sobre o alcance do rol de estabilidades que estariam contempladas no art. 499 da CLT. Apenas a decenal? Outras modalidades de estabilidade? Se sim, quais seriam e também quais os critérios para definir pela vinculação de estabilidades à hipótese de exclusão?

Em que pese a dificuldade em tratar de temas que limitem direitos dos trabalhadores, há necessidade de nos debruçarmos sobre a letra da lei na busca de conferir efetividade à vontade do legislador.

Referida limitação tem de ser entendida como exceção à regra maior que continua válida e cumprindo seu papel social. Noutras palavras, não se está diante de uma flexibilização do instituto da estabilidade provisória de emprego, mas tão somente de observância de um comando legal indicativo de que não se coadunam estabilidade provisória e ocupação de cargo de confiança.

Defendemos a tese de que qualquer análise de pertinência sobre qual estabilidade seria contemplada pela regra de exceção admitiria interpretação subjetiva não prevista em Lei. Assim, a primeira conclusão deve ser a de que ou o art. 499 da CLT contempla todas as modalidades de estabilidade ou 46 - Revista do Curso de Direito da Faculdade de Humanidades e Direito, v. 14, n. 14, 2017 


\section{A ESTABILIDADE NO EMPREGO E O EMPREGADO EM FUNÇÃO DE CONFIANÇA}

apenas a decenal, esta última por ausência de dúvidas de que estava inserida junto dos demais dispositivos que regulamentavam tal matéria. A leitura proposta é a de que o art. 499 não trouxe expressamente qualquer limitação de alcance, de modo que os empregados ocupantes de cargo de confiança não têm direito à estabilidade provisória de emprego.

Forçoso reconhecer que para algumas modalidades de estabilidade seria menos traumático o afastamento da benesse, como no caso do dirigente sindical que é eleito pela categoria. Nesse caso, fica mais evidente que referido empregado passaria a gozar de uma proteção a que ele próprio "deu causa" no momento em que buscou a candidatura mesmo ocupando cargo de confiança. Noutro extremo, veja-se hipótese do empregado ocupando de cargo de confiança, cuja Convenção Coletiva de Trabalho prevê a estabilidade pré-aposentadoria. Nesse segundo cenário, a hipótese não é de um movimento preliminar que acaba por gerar a proteção contra a despedida arbitrária, mas sim de um benefício conquistado por toda categoria na negociação para fins de assinatura do instrumento coletivo. Mesmo com esse cenário diverso entre os institutos, o que não se desconhece, deve prevalecer o entendimento de que o art. 499 não excepcionou estabilidades por ele não contempladas.

$\mathrm{Na}$ verdade, o que se buscou foi a liberdade do empregador em manter perto de si, ocupando cargo de confiança, empregado que continue gozando de sua confiança, de modo que, cessada tal condição, tenha o primeiro a possibilidade de executar seus atos de gestão sem amarras legais que o obriguem a manter em seu quadro deliberativo pessoa que não mais preencha as condições de fidúcia.

Algumas decisões judiciais ${ }^{6}$, como fundamento para reforçar a conclusão pela ausência de estabilidade para o

6 Acórdão No: 20050890578, Processo TRT/SP Nº: 00062200302602004 Recurso Ordinário - 26 VT de São Paulo Recorrente: Dagoberto Vieira Recorrido: Companhia de Engenharia de Trafego CET 
ocupante de cargo de confiança, também exploram o art. 37, II, da Constituição Federal, haja vista que tal dispositivo estabelece a necessidade de concurso público para investidura em cargo ou emprego público, porém ressalva a situação das "nomeações para cargo em comissão declarado em lei de livre nomeação e exoneração". Em que pese não atrelado à iniciativa privada, o dispositivo já foi invocado para reforçar a validade do art. 499 da CLT.

A decisão do TST que demandou a presente abordagem, deu-se no Recurso de Revista ${ }^{\circ}$ TST-E-ED-RR-11270089.2008.5.22.00047 . A $6^{\text {a }}$ Turma conheceu do Recurso de Re-

7 EMBARGOS EM EMBARGOS DE DECLARAÇÃO EM RECURSO DE REVISTA. ESTABILIDADE DO DIRIGENTE SINDICAL. FUNÇÃO DE CONFIANÇA. INCOMPATIBILIDADE. IMPOSSIBILIDADE DE REINTEGRAÇÃO. CONVERSÃO EM INDENIZAÇÃO. A Turma, equacionando lide em que se postula reintegração à função de confiança por força de estabilidade sindical, embora haja firmado tese no sentido da incompatibilidade entre os institutos, decidiu por ponderar valores e converter a reintegração em indenização pelo tempo restante de garantia decorrente da estabilidade sindical tomando como parâmetro salário condizente com o primeiro cargo efetivo, ou seja, o cargo efetivo de salário mais elevado na organização da empresa, conforme se apurar em liquidação de sentença. Todavia, a função de livre nomeação reveste-se de caráter precário e alicerça-se no elemento fidúcia, de maneira que os interesses do empregador que a deposita sejam defendidos por aquele empregado a quem conferida, prioritariamente. Daí a previsão legal de que a função é de livre nomeação e livre exoneração, porque, cessando o mencionado elemento de confiança, não há como manter-se o vínculo laboral. Logo, em princípio, o reconhecimento de garantia de emprego, ainda que decorrente de estabilidade sindical assegurada no art. $8^{\circ}$, VIII, da Constituição Federal, implicaria perpetuar o trabalhador que exerce função de confiança, o que, como visto, afronta o art. 499 da CLT. Por corolário, afigura-se incompativel a conversão de estabilidade de dirigente sindical, em semelhante situação, em indenização com base em salário de cargo efetivo nunca exercido pelo empregado. Com efeito, a conversão determinada no acórdão embargado culmina, por via transversa, por validar a tese da estabilidade provisória do trabalhador que exerce exclusivamente e desde a contratação cargo de confiança. Embargos de que se conhece e a que se dá provimento. Ministro Relator dos Embargos: MÁRCIO EURICO VITRAL AMARO.

48 - Revista do Curso de Direito da Faculdade de Humanidades e Direito, v. 14, n. 14, 2017 


\section{A ESTABILIDADE NO EMPREGO E O EMPREGADO EM FUNÇÃO DE CONFIANÇA}

vista e deu parcial provimento para converter a reintegração em indenização. O eminente Ministro Relator identificou que o Regional reconheceu que o reclamante ocupava cargo de confiança, mas rechaçou a excludente do art. 499 da CLT. Ainda, o Ministro Relator reconheceu a validade da referida excludente da estabilidade, mas apontou uma incompatibilidade entre os dois institutos, quais sejam, garantia de emprego e exceção do art. 499 da CLT. Diante disso, acabou por inovar ao propor desfecho que convertia a estabilidade em indenização. Temos crítica a esta saída proposta, pois não existia lacuna a merecer uma proposta sopesada pelos Ministros do TST. A Lei é clara ao excluir a estabilidade aos ocupantes de cargo de confiança. Assim, pareceu-nos mais correta a decisão definitiva tomada pela Subseção I Especializada em Dissídios Individuais do Tribunal Superior do Trabalho, no recurso de Embargos do reclamado, em restabelecer a sentença que havia indeferido o pedido de reintegração.

Por fim, importante destacar que a decisão foi proferida por maioria de votos e que ainda conviveremos com certa insegurança jurídica até que haja uniformização do tema.

\section{CONCLUSÃO}

Por todo o exposto no presente trabalho e amparado na decisão judicial proferida pelo TST, o art. 499 da CLT deve ser assimilado como incidente sobre as diferentes modalidades de estabilidade provisória. Admitir-se análises que passem por "escolhas" de quais seriam ao referido dispositivo legal vinculadas, quais não, geraria interpretação subjetiva sem respaldo legal. Assim, em que pese o precedente do TST invocado para o presente estudo trazer hipótese de estabilidade do dirigente sindical, entende-se que as demais também devem ter o mesmo desfecho na hipótese concreta. 


\section{REVISTA DO CURSO DE DIREITO}

\section{BIBLIOGRAFIA}

BARROS, Alice Monteiro de. Curso de Direito do Trabalho. 2. ed. São Paulo: LTr, 2006.

BRASIL. TRIBUNAL SUPERIOR DO TRABALHO. Disponivel em: $\leq$ http://www. tst.gov.br/ $\geq$. Acesso em 21.12.2016

BRASIL. Constituição da República Federativa do Brasil. Disponível em: $\leq$ http://www.planalto.gov.br/ccivil_03/constituicao/constituicaocompilado. $\mathrm{htm} . \geq$ Acesso em 15.12.2016

DELGADO, Maurício Godinho. Curso de Direito do Trabalho. São Paulo: LTr, 2012.

GARCIA, Gustavo Filipe Barbosa. Curso de Direito do Trabalho. São Paulo: Forense, 2012.

MARTINS, Sérgio Pinto. Direito do Trabalho. 22. ed. São Paulo: Atlas, 2006. NASCIMENTO, Amauri Mascaro. Iniciação ao direito do Trabalho. 2. ed., São Paulo: Saraiva, 2007. 